\title{
Possible Active Transport Mechanism in Pharmacokinetics of Flunixin-Meglumin in Rabbits
}

\author{
Yoshie MIYAZAKI ${ }^{1)}$, Yoshihiro HORII ${ }^{1,2,3)}$, Naohiro IKENAGA ${ }^{1)}$, Minoru SHIMODA ${ }^{1)}$ and Eiichi KOKUE ${ }^{1)}$ \\ ${ }^{1)}$ Laboratory of Veterinary Pharmacology, Faculty of Agriculture, Tokyo University of Agriculture and Technology, Fuchu, Tokyo 183- \\ $8509,{ }^{2)}$ Research Laboratoties, Animal Science Division, Dainippon Pharmaceutical Co., Ltd., Ikeda, Osaka $563-0011$ and ${ }^{3)}$ United \\ Graduate School of Veterinary Sciences, Gifu University, 1-1 Yanagido, Gifu 501-1193, Japan
}

(Received 22 January 2001/Accepted 17 April 2001)

\begin{abstract}
The plasma and urine kinetics of flunixin-meglumin (FNX, $2 \mathrm{mg} / \mathrm{kg}$, i.v.) in rabbits were examined. Unusual pharmacokinetic profiles were obtained, including high binding percentage with plasma protein $(>99 \%)$, a short elimination half-life $(<4 \mathrm{hr})$ and a relatively large $\mathrm{Vd}$-area $(0.5 \mathrm{~L} / \mathrm{kg})$. These profiles indicate that some active transport mechanisms are involved in FNX disposition. The recovery of FNX from urine was approximately $9 \%$ of the dose within $24 \mathrm{hr}$ following the injection. The estimated renal clearance of the unbound drug nearly corresponded to the renal blood flow rates, indicating that active tubular secretion in the renal re-absorptive tract may be involved in the disposition. The effect of a concomitant administration of pravastatin (PV) on FNX disposition was also examined. PV is a representative substrate of a transporter in human liver cells (OATP-2). After the PV administrations, the Vd-area of FNX and total body clearance markedly decreased, indicating that FNX is actively taken up and metabolized in liver cells by an OATP-2 like transporter. In conclusion, there are at least 2 active transport pathways for FNX pharmacokinetics in rabbits, one is renal tubular secretion and the other is in the sinusoidal section of the liver.

KEY WORDS: active transport, flunixin-meglumin, OATP-2, pharmacokinetics, rabbit.
\end{abstract}

J. Vet. Med. Sci. 63(8): 885-888, 2001

Flunixin-meglumin (FNX) is a popular non-steroidal anti-inflammatory drug (NSAID) used by veterinarians for treating a variety of animals. Many scientific reports have been published on this drug, some of which defined the characteristic pharmacokinetic profiles of FNX, such as short half-life and ultra-high binding percentages with plasma albumin. The plasma half-life was reported to be approximately $3 \mathrm{hr}$ in lactating cattle [1] and dogs [5], $2 \mathrm{hr}$ in cats [10] and $1.5 \mathrm{hr}$ in horses [14]. Despite short half-life values, the plasma protein binding fraction was higher than $98 \%$ in these animals.

In general, the elimination rate for drugs which have high plasma binding percentage is slow, because both renal filtration and influx of drugs into liver cells for drug metabolism are largely limited to the free drug fraction in plasma. Accordingly, it is reasonable to consider that some active transport pathways may be involved in the pharmacokinetics of FNX. In fact, there have been several reports which describe the involvement of active transport pathways in FNX disposition, for instance, the renal clearance of the unbound drug is much higher than the glomerular filtration rate in horses after FNX injection [14], suggesting that renal excretion of FNX is mainly due to active tubular secretion or an organic anion transport system. Other data shows that total body clearance is much higher than liver plasma flow in rats (unpublished data), suggesting an active uptake by liver cells in rats. Also, Hardee et al. reported that the Vdarea of FNX is more than $1 \mathrm{~L} / \mathrm{kg}$ in non-lactating cows [4], suggesting that an active transport pathway may be involved

\footnotetext{
* Correspondence to: Kokue, E., Laboratory of Veterinary Pharmacology, Faculty of Agriculture, Tokyo University of Agriculture and Technology, Fuchu, Tokyo 183-8509, Japan.
}

in the distribution phase in the cows.

In the present study, we examined the pharmacokinetics of FNX in rabbits, with emphasis on the involvement of active transport mechanisms, in both the elimination and distribution phases.

\section{MATERIALS AND METHODS}

The experiments were conducted in accordance with the guidelines for the care and use of laboratory animals, Faculty of Agriculture, Tokyo University of Agriculture and Technology.

Animals and drugs: A total of 26 rabbits (Japanese White, adult male, 3-4 kg body weight, Funabashi Farm Co., Ltd., Chiba, Japan) were used after they had fasted overnight. An injectable FNX formulation (Banamine ${ }^{\circledR}$, FNX $50 \mathrm{mg} / \mathrm{mL}$, Dainippon Pharmaceutical Co. Ltd., Osaka, Japan) and crystalline pravastatin (PV, Mevarotin ${ }^{\circledR}$, Sankyo Pharmaceutical Co., Ltd., Tokyo, Japan) were obtained from the above noted companies. The PV was dissolved in distilled water immediately preceding the intravenous injection.

Pharmacokinetic study: Flunixin-megulmin (FNX, $2 \mathrm{mg}$ / $\mathrm{kg})$ with or without PV $(83 \mathrm{mg} / \mathrm{kg}$ or $166 \mathrm{mg} / \mathrm{kg})$ was intravenously injected. The blood samples were collected serially at 1, 2, 4, 6 and $8 \mathrm{hr}$ after dosing, treated immediately with EDTA, and centrifuged at 2,000 $g$ for $10 \mathrm{~min}$ to separate the plasma. Urine samples were collected using a metabolic cage at 6 and $24 \mathrm{hr}$ after dosing. The urine samples were centrifuged at 5,000 $\mathrm{g}$ for $5 \mathrm{~min}$. All the samples were stored at $-20^{\circ} \mathrm{C}$ until analysis.

A two-compartment open model was used for pharmacokinetic analysis of FNX. Pharmacokinetic parameters of the 
bi-exponential equation were obtained using a curve fitting program MULTI [16]. The area under the plasma concentration vs time curve from zero to infinity (AUC) was calculated by application of the trapezoidal method to the last measured plasma concentration and extrapolation to infinity. The total body clearance (CLtot) was calculated by dose/AUC. The volume of distribution (Vd-area) was calculated by dividing CLtot by the slope in the elimination phase.

In vitro plasma protein-binding study: Plasma for the in vitro plasma binding study was obtained from four healthy rabbits. A $0.95 \mathrm{~mL}$ aliquot of plasma, spiked with a concentration of FNX $200 \mu \mathrm{g} / \mathrm{mL}$ solutions $(0.05 \mathrm{~mL})$ was incubated at $37^{\circ} \mathrm{C}$ for $10 \mathrm{~min}$ to allow drug-plasma protein binding equilibrium. The plasma was then pipetted into the sample reservoir of the ultra filtration device, Centrifree Micro-partition System ${ }^{\circledR}$ (Grace Japan KK-Amicon, Tokyo, Japan), and centrifuged at 2,000 $g$ for $10 \mathrm{~min}$. The filtrate (app. $100 \mu \mathrm{L}$ ) was analyzed immediately after centrifugation. The percentage of plasma binding was calculated as follows:

Binding percentage $(\%)=$

$\{$ (Total concentration - Unbound concentration $) \div$ Total Concentration $\} \times 100$

Determination of FNX in plasma and urine: FNX in plasma and urine was determined using HPLC with an UV detector. The detection limit in our method was $46 \mathrm{ng} / \mathrm{mL}$ of FNX. The apparatuses consisted of a C8 analytical column $\left(5 \mu \mathrm{m}, 4.6 \times 300 \mathrm{~mm}\right.$, RP-8, Lichrospfer ${ }^{\circledR}$, Merck, Darmstadt, Germany), a loop injector (7125, Rheodyne Cotani, California, U.S.A.), an UV-spectrophotometric detector (SPD-6A, Shimadzu, Kyoto, Japan), a pump (LC-9A, Shimadzu) and a data processor (Chromatopack C-R4A, Shimadzu). The mobile phase was a mixture of distilled water adjusted to $\mathrm{pH} 3.0$ by concentrated acetic acid and acetonitrile $(50: 50, \mathrm{vol} / \mathrm{vol})$. The flow rate was $0.8 \mathrm{~mL} / \mathrm{min}$. The applied wavelength of the detector was $281 \mathrm{~nm}$.

Plasma samples were deproteinized by adding equal volumes of $0.5 \mathrm{M} \mathrm{HClO} 4$ and centrifuged at $5,000 \mathrm{~g}$ for $5 \mathrm{~min}$. The supernatant was filtered though a $0.45 \mu \mathrm{m}$ filter (Chromatodisk 4A, Biofield, Tokyo, Japan) and injected into the HPLC column. The urine samples were diluted with distilled water (10-20 fold), and after filtration through a 0.45 $\mu \mathrm{m}$ filter were injected into the HPLC column.

Statistics: Pharmacokinetic data from each group were analyzed by two-way ANOVA after the homogeneity of variance was confirmed among the groups using the Bartlett test. A significant difference between the groups was confirmed when $\mathrm{p}<0.05$, using Scheffe's multiple comparison test.

\section{RESULTS}

Pharmacokinetic profiles of FNX in rabbits: The binding percentage of FNX in plasma was $99.74 \pm 0.32 \%(n=5)$ at 10 $\mu \mathrm{g} / \mathrm{mL}$ concentration, from the in vitro experiment.

As shown in Fig. 1, the plasma concentration-time curve

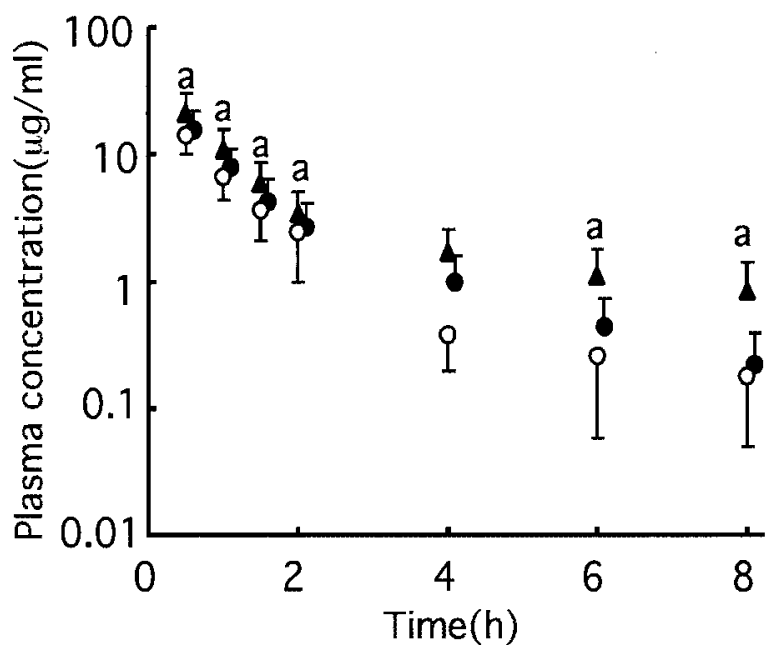

Fig. 1. Plasma concentration-time curves of FNX (2 mg/kg) after intravenous injections with or without PV. $\bigcirc$ : FNX alone, $\mathrm{FNX}+\mathrm{PV}(83 \mathrm{mg} / \mathrm{kg}), \mathbf{\Delta}: \mathrm{FNX}+\mathrm{PV}(166 \mathrm{mg} / \mathrm{kg})$. a) represents statistical significance $(0.05<)$.

showed a biphasic decline after intravenous injection of $\mathrm{FNX}$ at $2 \mathrm{mg} / \mathrm{kg}$ in rabbits.

The pharmacokinetic parameters after intravenous injection of FNX are presented in Table 1. A short half-life, relatively large $\mathrm{Vd}$-area, high intrinsic renal clearance (CLrub) and intrinsic liver clearance (CLtotub) were detected. The value of CLrub $46.2 \mathrm{~mL} / \mathrm{min} / \mathrm{kg}$ was much larger than the renal filtration rate (app. $2 \mathrm{~mL} / \mathrm{min} / \mathrm{kg}$ ), and CLtotub (546 $\mathrm{mL} / \mathrm{min} / \mathrm{kg}$ ) was much larger than the blood flow rate into the liver (app. $70 \mathrm{~mL} / \mathrm{min} / \mathrm{kg}$ ).

Effects of PV on FNX pharmacokinetics: The plasma FNX concentration-time curve shifted upwards after PV coadministration. At most sampling points, plasma concentrations of FNX with PV $166 \mathrm{mg} / \mathrm{kg}$ were significantly higher than those of FNX alone or with PV $83 \mathrm{mg} / \mathrm{kg}$ (Fig. 1).

As shown in Table 1, some pharmacokinetic parameters of FNX changed with the PV co-administration. The CLtot and Vd-area decreased significantly, while the A intercept for FNX rose significantly. The half-life of FNX did not change after the co-administration of PV.

\section{DISCUSSION}

In the present study, a short half-life $(<4 \mathrm{hr})$ and a high binding percentage with plasma protein $(>99 \%)$ were confirmed after the intravenous injection of FNX in rabbits. Similar pharmacokinetic profiles of FNX have also been reported in other animals, including dogs [5], cats [10], horses [14] and rats (unpublished data).

One of the characteristic profiles obtained in the present study was the large Vd-area of FNX (app. $0.5 \mathrm{~L} / \mathrm{kg}$ ), compared with the other NSAIDs. The values of Vd-area in most NSAIDs are usually less than $0.1 \mathrm{~L} / \mathrm{kg}$, because of 
Table 1. Plasma and urinary kinetics after the administration of FNX alone and FNX with substantial doses of PV

\begin{tabular}{lccc}
\hline & $\begin{array}{c}\text { FNX }(2 \mathrm{mg} / \mathrm{kg}) \\
(\mathrm{n}=5)\end{array}$ & $\begin{array}{c}\text { FNX+PV }(83 \mathrm{mg} / \mathrm{kg}) \\
(\mathrm{n}=5)\end{array}$ & $\begin{array}{c}\mathrm{FNX}+\mathrm{PV}(166 \mathrm{mg} / \mathrm{kg}) \\
(\mathrm{n}=5)\end{array}$ \\
\hline $\mathrm{A}(\mu \mathrm{g} / \mathrm{mL})$ & $30.3 \pm 7.4$ & $31.7 \pm 14.0$ & $56.3 \pm 9.9^{\mathrm{a}, \mathrm{b})}$ \\
$\alpha(1 / \mathrm{h})$ & $1.06 \pm 0.20$ & $1.96 \pm 0.30$ & $2.06 \pm 0.46$ \\
$\mathrm{~B}(\mu \mathrm{g} / \mathrm{mL})$ & $0.701 \pm 0.355$ & $4.65 \pm 4.14$ & $5.64 \pm 3.64$ \\
$\beta(1 / \mathrm{h})$ & $0.195 \pm 0.062$ & $0.372 \pm 0.091$ & $0.261 \pm 0.097$ \\
$\mathrm{~T} 1 / 2 \beta(\mathrm{h})$ & $3.87 \pm 1.27$ & $1.97 \pm 0.57$ & $2.93 \pm 0.97$ \\
Vd-area $(\mathrm{L} / \mathrm{kg})$ & $0.460 \pm 0.148$ & $\left.0.198 \pm 0.061^{\mathrm{a}}\right)$ & $0.163 \pm 0050^{\mathrm{a})}$ \\
CLtot $(\mathrm{mL} / \mathrm{min} / \mathrm{kg})$ & $1.42 \pm 0.32$ & $1.20 \pm 0.40$ & $0.647 \pm 0.050^{\mathrm{a})}$ \\
CLtotub $(\mathrm{mL} / \mathrm{min} / \mathrm{kg})$ & $546 \pm 154$ & $462 \pm 154$ & $\left.249 \pm 40^{\mathrm{a}}\right)$ \\
Urinary recovery $(\%)$ & $8.93 \pm 2.69$ & $\mathrm{ND}$ & $\mathrm{ND}$ \\
CLr $(\mathrm{mL} / \mathrm{min} / \mathrm{kg})$ & $0.120 \pm 0.010$ & $\mathrm{ND}$ & $\mathrm{ND}$ \\
CLrub $(\mathrm{mL} / \mathrm{min} / \mathrm{kg})$ & $46.2 \pm 4.0$ & $\mathrm{ND}$ & $\mathrm{ND}$ \\
\hline
\end{tabular}

The animals were administered FNX $2 \mathrm{mg} / \mathrm{kg}$ with or without PV (i.v.).

Urine was sampled up to $48 \mathrm{hr}$ after the drug administration.

a) denotes significant difference from FNX alone $(\mathrm{p}<0.05)$.

b) denotes significant difference from FNX + PV83 mg/kg ( $<<0.05)$.

ND: not determined.

Each value is expressed as mean $\pm \mathrm{SD}$.

" $\mathrm{n} "=$ the numbers of experiment.

FNX's high binding percentages with plasma protein $(>98 \%)$ [2]. However, some reports have shown a relatively large Vd-area for FNX such as, $1 \mathrm{~L} / \mathrm{kg}$ and $0.3 \mathrm{~L} / \mathrm{kg}$ in cattle [4] and dogs [5], respectively, and $0.16 \mathrm{~L} / \mathrm{kg}$ for ibuprofen in dogs [13] and $0.20 \mathrm{~L} / \mathrm{kg}$ in ponies [15].

These large Vd-areas of FNX remind us of the involvement of active transport mechanisms in the distribution phase. Nowadays, 3 kinds of organic anion transporters have been demonstrated in human liver cells [7]; among them, organic anion transporter type-2 (OATP-2) has been noted to be involved in the uptake of many drugs into liver cells. Similar transporters to this OATP-2 were confirmed in the rat liver, OATP-1/4 $(3,17)$. It has been reported that endogenous reduced folate [8], PV [9, 18] and methotrexate [11] are the substrate of these transporters. Supposing that rabbits might also have a similar transporter in their liver, we examined the pharmacokinetics of FNX in rabbits using concomitant administration of a large amount of PV, expecting to block possible FNX uptake into the liver cells by means of PV. PV, a therapeutic agent for hyper-lipoproteinemias, is a representative substrate of OATP-2.

The Vd-area of FNX decreased by approximately $40 \%$ after the concomitant administration of PV with FNX, indicating that FNX is taken up in the liver via an OATP-2 like transporter in rabbits. In addition, CLtot decreased by approximately $50 \%$ after the concomitant administration of $\mathrm{PV}$, which may be the result of blockage in the transporter passage, in turn followed by the reduction of FNX metabolism and/or biotransformation. Accordingly, it can be considered that a large fraction of FNX is actively transported via an OATP-2 like transporter into rabbit liver cells for metabolization.

In rabbits, the elimination of FNX was mainly due to nonrenal routes including biotransformation in the liver. The renal clearance was only one tenth of the total body clearance (Table 1). However, the inherent renal clearance (CLrub) was much higher than the renal filtration rate, app. $2 \mathrm{~mL} / \mathrm{min} / \mathrm{kg}$. This large CLrub can't be explained without the involvement of active tubular secretion in the FNX disposition in rabbits. Soma et al. [14] reported that the urinary excretion of FNX in horses was approximately a $60 \%$ fraction of the dose within $12 \mathrm{hr}$ after the administration, despite the high binding percentage with plasma protein (approximately $99 \%$ ), indicating that an active transporter in the horse kidney is involved in FNX excretion.

A large fraction of FNX is removed from the body via hepatic clearance, therefore, competitive CYP enzyme metabolism is a possible consideration for FNX and PV. However, because the affinity of PV to CYP enzyme was quite low, such competition must be negligible $[6,12]$.

In conclusion, there are at least 2 active transport pathways involved in the pharmacokinetics of FNX in rabbits: renal tubular secretion and OATP-2 like transporter in the sinusoidal section of the liver. The renal transporter may be involved in renal excretion of FNX, and the liver transporter in the distribution and total body clearance of FNX in rabbits. Reviewing the pharmacokinetic profiles of NSAIDs including FNX, large inter-species differences can be found in the pharmacokinetic parameters such as half-life, $\mathrm{Vd}$-area or total body clearance. These species differences may be due to the inherent transporter in animal species. It is important to note that the extra-label use of NSAIDs must be prudent.

ACKNOWLEDGMENTS. We are grateful to Sankyo Pharmaceutical Co. (Tokyo, Japan) for donating crystalline pravastatin. We also thank Mrs. Kate Mason and Kayoko Kimura for correcting our English. 


\section{REFERENCES}

1. Anderson, K. L., Neff-Davis, C. A., Davis, L. E. and Bass, V. D. 1990. Pharmacokinetics of flunixin meglumine in lactating cattle after single and multiple intramuscular and intravenous administrations. Am. J. Vet. Res. 51: 1464-1467.

2. Debacker, P., Braeckman, R., Belpaire, F. and Debackere, M. 1980. Bioavailability and pharmacokinetics of phenylbutazone in the cow. J. Vet. Pharmacol. Ther. 3: 29-33.

3. Dumont, M., Jacquemin, E., D7Hont, C., Descout, C., Cresteil, D., Haouzi, D., Descrochers, M., Stieger, B., Hadchouel, M. and Erlinger, S. 1997. Expression of the liver Na+-independent organic anion transporting polypeptide (oatp-1) in rats with bile duct ligation. J. Hepatol. 27: 1051-1056.

4. Hardee, G.E., Smith, J.A. and Harris, S.J. 1985. Pharmacokinetics of flunixin meglumine in the cow. Res. Vet. Sci. 39: 110112.

5. Hardie, E., Hardee, G. E. and Rawlings, C. A. 1985. Pharmacokinetics of flunixin meglumine in dogs. Am. J. Vet. Res. 46: 235-237.

6. Horsmans, Y., Desager, J.P., van den Berge, V., Abrassart, M. and Harvengt, C. 1993. Effect of simvastatin and pravastatin on $6 \beta$-hydroxycortisol excretion, a potential marker of cytochrome P-453 3A. Pharmacol. Res. 28: 243-248.

7. Hsiang, B., Zhu, Y., Wang, Z., Wu, Y., Sasseville, V., Yang, W.P. and Kirchgessner, T.G. 1999. A novel human hepatic organic anion transporting polypeptide (OATP2). Identification of a liver-specific human organic anion transporting polypeptide and identification of rat and human hydroxymethylglutaryl-CoA reductase inhibitor transporters. J. Biol. Chem. 274: 37161-37168.

8. Kusuhara, H., Han, Y. H., Shimoda, M., Kokue, E., Suzuki, H. and Sugiyama, Y. 1998. Reduced folate derivatives are endogenous substrates for cMOAT in rats. Am. J. Physiol. 275:
G789-796.

9. Ishigami, M., Tokui, T., Komai, T., Tsukahara, K., Yamazaki, M. and Sugiyama, Y. 1995. Evaluation of the uptake of pravastatin by perfused rat liver and primary cultured rat hepatocytes. Pharm. Res. 12: 1741-1745.

10. Lees, P. and Taylor, P. M. 1991. Pharmacodynamics and pharmacokinetics of flunixin in the cat. Br. Vet. J. 147: 298-305.

11. Masuda, M., Iizuka, Y., Yamazaki, M., Nishigaki, R., Kato, Y., Niinuma, K., Suzuki, H. and Sugiyama, Y. 1997. Methotrexate is excreted into the bile by canalicular multispecific organic anion transporter in rats. Cancer. Res. 57: 3506-3510.

12. Neuvonem, P.J., Kantola, T. and Kivisto, K.T. 1998. Simvastatin but not pravastatin is very susceptible to the interaction with the CYP 3A4 inhibitor itraconazole. Clin. Pharmacol. Ther. 63: $332-341$.

13. Scherkl, R. and Frey, H. H. 1987. Pharmacokinetics of ibuprofen in the dogs. J. Vet. Pharmacol. Ther. 10: 261-265.

14. Soma, L. R., Behrend, E., Rudy, J. and Sweeney, R. W. 1988. Disposition and excretion of flunixin meglumine in horses. Am. J. Vet. Res. 49: 1894-1898.

15. Vandenbossche, G. M. R., Bouckaert, S., De Muynck, C., Mommens, G., Van Zeveren, A. and Remon, J. P. 1992. Bioavailability of two ibuprofen oral paste formulations in fed or nonfed ponies. Am. J. Vet. Res. 53: 528-531.

16. Yamaoka, K., Tanigawara, Y., Nakagawa, T. and Uno, T. 1981. A pharmacokinetic analysis program (MULTI) for microcomputer. J. Pharmacobio-Dyn. 4: 879-885.

17. Yamazaki, M., Suzuki, H., Hanano, M., Tokui, T., Komai, T. and Sugiyama, Y. 1993. Na(+)-independent multispecific anion transporter mediates active transport of pravastatin into rat liver. Am. J. Physiol. 264: G36-44.

18. Ziegler, K. and Hummelsiep, S. 1993. Hepatoselective carriermediated sodium-independent uptake of pravastatin and pravastatin-lactone. Biochim. Biophys. Acta 1153: 23-33. 